\title{
237 EFFECT OF SURYANAMASKAR PRACTICE ON THE BODY COMPOSITION OF FEMALE STUDENTS
}

Shivesh Shukla Assistant Trainer, Magic Bus (NGO), Mumbai, Maharashtra, India

10.1136/bjsm.2010.078725.237

The present experiment was conducted on randomly selected 30 female students, their age ranging from 14 to 16 , intended to measure the effect of suryanamaskar practice on the body composition of female students. Estimated body fat percentage was assessed by skinfold caliper at the biceps, triceps, suprailiac and subscapular. The experiment was of 6 weeks, 5 days a week for duration of $30 \mathrm{~min}$. Percentage of fat is taken according to the assessment of body composition chart by JVGA Durnin and MM Rahaman. Paired t test was applied at the result was tested for significance 0.05 level. The obtained ' $t$ ' value between the pre-means of experimental group and control group was 0.18 which is less than the required value of 2.14 (0.05 level). The obtained ' $t$ ' value between the pre- and post-means of experimental group was 0.10 which is less than the required value of 2.14 ( 0.05 level). The ' $t$ ' value of the preand post-means of control group was 0.40 which is less than the required value of 2.14 (0.05 level). It shows that both the having similar total body fat of body composition. The ' $t$ ' value of the pre- and post-means of experimental group and control group was 0.01 which is very less than the required value of 2.14 (0.05 level). The finding reveals that no significant differences between the pre- and post-test of experimental and control group, may be attributed to the fact that the selected age group was active participant and have hectic schedule which keep the fat percentage to a very low level. This indicated that the suryanamaskar practice have no effect on the body composition of female students. 